\title{
Reliability of accelerometric measurement of physical activity in older adults-the benefit of using the trimmed sum
}

\author{
Ulrike Sonja Trampisch • Petra Platen • \\ Matthias Trampisch • Anna Moschny • Ulrich Thiem • \\ Timo Hinrichs
}

Received: 15 December 2011 / Accepted: 27 March 2012 / Published online: 22 April 2012

(C) The Author(s) 2012. This article is published with open access at Springerlink.com

\begin{abstract}
There is general consensus that physical activity is important for preserving functional capacities of older adults and positively influencing quality of life. While accelerometry is widely accepted and applied to assess physical activity in studies, several problems with this method remain (e.g., low retest reliability, measurement errors). The aim of this study was to test the intra-instrumental retest reliability of a wrist-worn accelerometer in a 3-day measurement of physical activity in older adults and to compare different estimators. A sample of 123 older adults $(76.5 \pm$ 5.1 years, $59 \%$ female) wore a uniaxial accelerometer continuously for 1 week. The data were split into two repeated measurement values (week set) of 3 days each. The sum, the 80-99th quantiles and the 80-99th trimmed sums were built for each week set. Retest reliability was assessed for each estimator and graphically demonstrated by Bland-Altman plots. The intraclass correlation of the retest reliability ranged from 0.22 to 0.91 . Retest reliability increases when a more robust estimator than the overall sum is used. Therefore, the trimmed sum can be recommended as a conservative estimate of the physical activity level of older adults.
\end{abstract}

Keywords Aged - Reproducibility of results $\cdot$ Activities of daily living $\cdot$ Bias (epidemiology)

U. S. Trampisch $(\bowtie) \cdot$ P. Platen $\cdot$ A. Moschny $\cdot$ T. Hinrichs Department of Sports Medicine and Sports Nutrition, Ruhr-University Bochum, 44801 Bochum, Germany

e-mail: ulrike-trampisch@amib.rub.de

U. S. Trampisch $\cdot$ M. Trampisch $\cdot$ U. Thiem

Department of Medical Informatics, Biometry and Epidemiology,

Ruhr-University Bochum,

44801 Bochum, Germany

\section{Introduction}

There is general consensus that physical activity is important for preserving functional capacities of older adults and for positively influencing quality of life $[7,12]$. To measure physical activity in studies, a variety of direct (e.g., pedometer) or indirect (e.g., questionnaires) methods is used [18, 20]. The measurement methods differ with regard to their quality, criteria validity and retest reliability, costs and acceptance by study participants, and depend closely on the feasibility within the study design. At present, no gold standard for the assessment of physical activity has been established [18, 28].

Among direct methods to measure physical activity, accelerometry is accepted and widely applied. An accelerometer is worn on the body (e.g., at the hip, ankle, or wrist) measuring acceleration in up to three dimensions. In so doing, information on frequency, intensity, and duration of an individual's physical activity is collected, expressed in "counts per minute" (CPM). It is assumed that the amount of CPM is associated with the intensity of physical activity [5, 14]. To represent the average physical activity of an individual, a minimum of 3 -day measurement is suggested [28, 29].

Despite the widespread use, direct measurement of physical activity using an accelerometer remains challenging [18, 31]. There is-for example-no consensus on the type of accelerometer to use $[1,18,28]$, nor is there agreement as to the part of the body on which it should be worn [9], just recommendations for different target groups, e.g., for older adults exist $[4,6,16,21]$. Older adults frequently perform physical activity with light to moderate intensity, such as housekeeping, gardening, or walking for leisure [11]. In order to take these activities into account, some authors recommend the use of a wrist-worn uniaxial accelerometer 
$[4,6,16,21]$, since movements mainly occur in the upper body and arms (e.g., the wrist-worn "Actiband" AB64 uniaxial accelerometer, Cambridge Neurotechnology Ltd., UK).

Despite the wide use of accelerometry-based measurement of physical activity in all kinds of studies, data on the retest reliability are seldom published [16]. This is true for the uniaxial wrist-worn Actiband accelerometer itself, as well as for other accelerometers in general. The only published data on the retest reliability of the Actiband was found in Rowe et al. [19]. They found a high interinstrumental retest reliability of two Actibands which were worn simultaneously during a test on a treadmill (ICC= 0.98; $95 \%$ CI: 0.91-0.99). However, the study was performed with ten 10 to 11-year-old boys in a laboratory environment, comparing two different Actibands. Therefore, these results cannot directly be adopted for the measurement of activities of daily life in communitydwelling older adults within a nonlaboratory situation.

Maybe the reason for the limited data of the accelerometerbased measurement of physical activity is partly explained by the disappointing results of the analysis of retest reliability. Usually, the sum of CPM or the mean CPM, collected over a period of a few days and divided by the number of days, [26, $28,30]$, is used to express the average amount of physical activity of an individual. The resulting "average counts per day" often show tremendous intra- and inter-individual variability [9]. This variability may be partly explained by outliers of the CPM measured by the accelerometer. Outliers are multiples of reasonable CPM values. These values are defined as measurement errors, since they are clearly due to methodological issues of the manufacture and cannot be achieved by any kind of physical activity. Consequently, using the sum or the mean of CPM which still include the outliers cannot result in high retest reliability. Unfortunately, a standardized recommendation on how to deal with outliers of accelerometry is lacking. Retest reliability might be low due to the outliers which account for the overall sum and not due the general missing possibility of reproducing the results. Orsini et al. [17], for example, defined CPM greater than 20,000 as malfunction of the accelerometer without further explanations on the cut-point they chose. These data were then set as missing and thereby excluded from analyses. Instead of defining a certain cut-point for each accelerometer, we would like to suggest a different approach. In order to enhance the retest reliability, an alternative and more robust estimator that is less sensitive to outliers/measurement errors might be needed. The trimmed (or truncated) sum may be an alternative estimator. The trimmed sum is obtained by omitting a certain percentage of the most extreme observations (e.g., $5 \%$ of the low and $5 \%$ of the high end) and taking the sum of the rest. It is a robust measure of central tendency and is stable against abnormal extreme values (such as measurement errors/outliers), which get "trimmed" away [2]. Using the trimmed sum to express the average amount of physical activity of an individual instead of the overall sum of CPM may result in higher retest reliability.

The aim of the study was therefore to find a more robust estimator in order to account for outliers that occur by using accelerometry to measure physical activity. This more robust estimator will then be used to test the intra-instrumental retest reliability of a wrist-worn accelerometer in a 3-day measurement of physical activity in community-dwelling older adults. We hypothesized that using quantiles and the trimmed sum instead of the overall sum (which includes the outliers) of CPM will decrease the measurement error and increase the retest reliability.

\section{Methods}

The presented study was part of a validation study of a physical activity questionnaire for older adults [23-25]. Participants were recruited via 13 general practitioners in North-Rhine Westphalia, Germany during springtime. All patients, who visited the practice for any reason and fulfilled the inclusion criteria, were asked to become a participant of the study. The inclusion criteria were being 70 years or older, being legally competent and able to cooperate appropriately, and providing written informed consent. The exclusion criteria were life expectancy less than 6 months, being in a wheelchair or bedridden. Recruitment time within one general practitioner practice was 1 week. Body mass index $\left(\mathrm{kg} \times \mathrm{m}^{-2}\right)$ was computed from measured height and weight on a standard balance scale (Seca 862) and stadiometer (Seca 214, both: Seca, Germany). The study was approved by the Ethics Committee.

A sample of 123 community-dwelling older adults wore the Actiband AB64 uniaxial accelerometer (Cambridge Neurotechnology Ltd., UK) continuously for 1 week (7 days, $24 \mathrm{~h}$ per day). The Actiband is a lightweight device (12 g; size, $35 \times 15 \times 5 \mathrm{~mm})$ that measures and records vertical acceleration with a 1-min epoch. The device is waterproof.

In order to find a more robust estimator than the overall sum of CPM, the retest reliability of selected quantiles and trimmed sums was evaluated and compared to that of the overall sum of CPM. After participants had returned the Actiband to the study center, the complete data of 1 week were afterwards split into two repeated measurement values (week set) of 3 days each. The first set included the CPM data from Monday, Tuesday, and Wednesday; and the second set included the data from Thursday, Friday, and Saturday. Sunday was excluded. Assuming that a maximum of $20 \%$ of the CPM values at the high end of the distribution were due to outliers, these values were discarded by building two datasets each: the 80th, 85th, 90th, 95th and 
99th quantiles (Q80-Q99), and the 80, 85, 90, 95, and $99 \%$ trimmed sums (TS80-TS99). The CPM value of the, e.g., Q80 (80th quantile) is the value where $80 \%$ of the CPM values are less or equal to it and $20 \%$ are greater than or equal to the particular CPM value. To build the trimmed sums, only the high end of the CPM values was trimmed, since the low end contained a large number of null values (measured during sleep or physical inactivity), and then summed up. This means that the $(1-\beta)$ trimmed sum is calculated as

$\mathrm{TS}_{1-\beta}=\sum_{i=1}^{n} w_{i} \cdot \mathrm{cpm}_{i}$

where

$w_{i}=\left\{\begin{array}{l}1, \frac{i}{n} \leq 1-\beta \\ 0, \frac{i}{n}>1-\beta\end{array}\right.$

and $0 \leq \beta \leq 1$. The parameter $\beta$ defines the percentage of the trimming. For comparison, the special case of the overall sum $(\beta=0$, i.e., nothing is trimmed) will also be described.

Over the 1-week measurement period, 10,080 $[=7 \times$ (days) $\times 24$ (hours) $\times 60$ (minutes)] single values of CPM were collected per participant. Each original 3-day set consequently consisted of $4,320[=3 \times($ days $) \times 24$ (hours $) \times 60$ (minutes)] single values. The retest reliability was assessed by using the intraclass correlation (ICC A, 1) [15].

A Bland-Altman plot was used as a graphic assessment of the agreement of the 2 week sets where the difference between the 2 week sets is plotted against their mean for each subject [3]. The $95 \%$ limits of agreement, estimated by mean difference $\pm 1.96 \times$ standard deviation of the differences, provide an interval within which $95 \%$ of differences between measurements by the 2 -week sets are expected to lie.

\section{Results}

\section{Participants}

The anthropometric characteristics of the 123 participants (aged $76.5 \pm 5.1$ years, $59 \%$ female) of the study are shown in Table 1 .

\section{CPM}

The assessment of physical activity of older adults in this study showed measurement errors (outliers). Figure 1 shows the 1week measurement of a participant. This activity profile mainly shows CPM in between 0 (inactive) and 1,000, whereas five single values clearly exceed the usual level. These values can be defined as outliers. This occurrence was similar in physical activity profiles of other participants who were randomly chosen.

Retest reliability

The results of the retest reliability are summarized in Table 2 . The ICC of the retest reliability of the overall sum of CPM for the 3-day measurement was ICC $=0.77$ ( $95 \%$ confidence interval [CI]: 0.68-0.83). Using the quantiles, the ICC was between 0.22 (95 \% CI: $0.05-0.39$ ) and 0.91 (95 \% CI: 0.87-0.93). For the trimmed sum, the ICC was between 0.82 (95\% CI: 0.75 0.87 ) and 0.85 (95\% CI: $0.79-0.89$ ). The differences in the CPM from week set 1 and week set 2 show only moderate variations in the Bland-Altman plots using TS95 (Fig. 2).

\section{Discussion}

In order to measure physical activity within studies, accelerometry is a measurement technique which is widely applied. But this method is still afflicted with some peculiarities, e.g., measurement errors. In order to enhance the quality of data, we proposed to use more robust estimators such

Table 1 Characteristics of the study participants in total and broken down by sex

\begin{tabular}{|c|c|c|c|c|c|c|c|c|c|}
\hline & \multicolumn{3}{|l|}{ Total $n=123$} & \multicolumn{3}{|c|}{ Female $n=73(59 \%)$} & \multicolumn{3}{|l|}{ Male $n=50$} \\
\hline & Mean \pm SD & Min & Max & Mean \pm SD & Min & Max & Mean \pm SD & Min & Max \\
\hline Age (years) & $76.5 \pm 5.1$ & 70.1 & 98.6 & $77.2 \pm 5.8$ & 70.1 & 98.6 & $75.6 \pm 3.7$ & 70.2 & 85.5 \\
\hline Height (m) & $1.65 \pm 0.08$ & 1.47 & 1.86 & $1.60 \pm 0.06$ & 1.47 & 1.78 & $1.71 \pm 0.06$ & 1.54 & 1.86 \\
\hline Weight $(\mathrm{kg})$ & $81.2 \pm 14.5$ & 50.5 & 114.0 & $77.3 \pm 14.4$ & 50.5 & 114.0 & $86.8 \pm 12.7$ & 55.0 & 111.0 \\
\hline Body mass index $\left(\mathrm{kg} \times \mathrm{m}^{2}\right)$ & $29.8 \pm 4.4$ & 20.5 & 44.2 & $30.1 \pm 4.9$ & 20.5 & 44.2 & $29.5 \pm 3.6$ & 22.9 & 35.9 \\
\hline Sum CPM over 7 days & $619,084^{\mathrm{a}}$ & $430,340^{\mathrm{b}}$ & $820,977^{\mathrm{c}}$ & $692,898^{\mathrm{a}}$ & $426,588^{\mathrm{b}}$ & $875,139^{\mathrm{c}}$ & $594,925^{\mathrm{a}}$ & $429,553^{\mathrm{b}}$ & $708,919^{c}$ \\
\hline
\end{tabular}

$n$ number of participants, $S D$ standard deviation, $\min$ minimum, max maximum, $m$ meter, $\mathrm{kg}$ kilogram

${ }^{a}$ median

b $25 \%$ quantile

c $75 \%$ quantile 
Fig. 1 Listed count per minute during a 1 -week period $(10,080$ in total) and each value of the corresponding count per minute including five unreasonable high values (measurement errors). The solid vertical lines divide the 7 days of measurement from 1 day to another

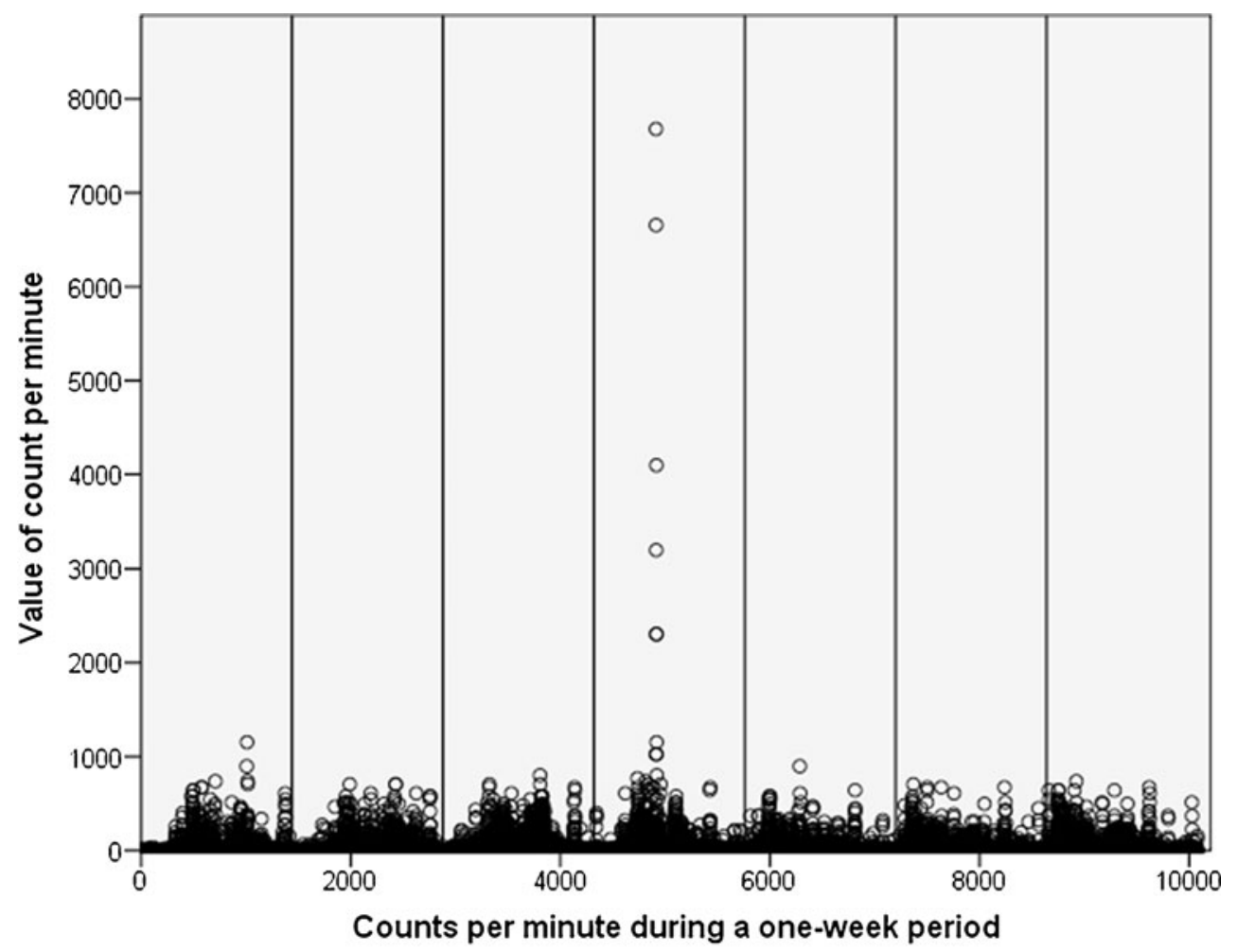

Table 2 Counts per minute of the sum, the quantile, and the trimmed sum including intraclass correlation

\begin{tabular}{|c|c|c|c|}
\hline & $\begin{array}{l}\text { WS1 mean } \pm \text { SD } \\
\text { WS2 mean } \pm \text { SD }\end{array}$ & Diff (WS1-WS2) \pm SD & ICC $(95 \% \mathrm{CI})$ \\
\hline Q80 & $\begin{array}{l}119 \pm 66 \\
115 \pm 62\end{array}$ & $4 \pm 30$ & $0.89(0.85 ; 0.92)$ \\
\hline Q85 & $\begin{array}{l}158 \pm 79 \\
153 \pm 74\end{array}$ & $5 \pm 33$ & $0.90(0.87 ; 0.93)$ \\
\hline Q90 & $\begin{array}{l}212 \pm 96 \\
205 \pm 87\end{array}$ & $6 \pm 39$ & $0.91(0.87 ; 0.93)$ \\
\hline Q95 & $\begin{array}{l}303 \pm 125 \\
294 \pm 107\end{array}$ & $9 \pm 57$ & $0.88(0.83 ; 0.91)$ \\
\hline Q99 & $\begin{array}{l}523 \pm 221 \\
525 \pm 359\end{array}$ & $-3 \pm 372$ & $0.22(0.05 ; 0.39)$ \\
\hline TS80 & $\begin{array}{l}69,773 \pm 49,938 \\
71,280 \pm 50,078\end{array}$ & $-1,508 \pm 28,406$ & $0.84(0.78 ; 0.88)$ \\
\hline TS85 & $\begin{array}{r}98,674 \pm 64,107 \\
100,978 \pm 63,797\end{array}$ & $-2,304 \pm 35,615$ & $0.85(0.79 ; 0.89)$ \\
\hline TS90 & $\begin{array}{l}136,415 \pm 80,600 \\
139,579 \pm 79,010\end{array}$ & $-3,165 \pm 44,821$ & $0.84(0.78 ; 0.89)$ \\
\hline TS95 & $\begin{array}{l}187,115 \pm 99,191 \\
192,271 \pm 97,347\end{array}$ & $-5,156 \pm 55,106$ & $0.84(0.78 ; 0.89)$ \\
\hline TS99 & $\begin{array}{l}248,356 \pm 119,996 \\
254,871 \pm 114,305\end{array}$ & $-6,514 \pm 70,062$ & $0.82(0.75 ; 0.87)$ \\
\hline $\begin{array}{l}\text { Overall } \\
\text { sum }\end{array}$ & $\begin{array}{l}273,470 \pm 127,960 \\
283,189 \pm 123,043\end{array}$ & $-9,720 \pm 85,596$ & $0.77(0.68 ; 0.83)$ \\
\hline
\end{tabular}

WS1 week set 1, WS2 week set 2, SD standard deviation, diff difference, ICC intraclass correlation, $95 \%$ CI $95 \%$ confidence interval as quantiles or trimmed sums as a summary measure of physical activity instead of the overall sum. These estimators were then analyzed in terms of retest reliability.

As assumed, both quantiles and trimmed sums CPM increased the retest reliability compared to the overall sum. This was true irrespective of the chosen cut off point (e.g., 80 or $95 \%$ ) above which the values were omitted (trimmed sum). We clearly showed that the retest reliability increases when using an estimator such as the TS95. We prefer to use the trimmed sum rather than a certain quantile. When using a quantile to describe the physical activity, it remains unclear whether this CPM value at a predefined quantile was achieved due to one intensive physical activity (e.g., running quickly to get to the bus once during the 3-day measurement period) irrespective of the remaining physical activity or if the person has a high average level of overall physical activity in general. In contrast to the quantiles, the trimmed sum accounts for this, and the average physical activity remains in the estimator. The trimmed sum allows a predefined (or estimated) error level $\beta$ of the used device to be selected, and then yields a single number which reflects all activities. Additionally, the trimmed sum is proportional to the weighted/truncated mean, which allows the calculation of average activity [13], e.g.

average activity $=\frac{1}{\sum_{i=1}^{n} w_{i}} \cdot \mathrm{TS}_{1-\beta}$ 
Fig 2 A $95 \%$ trimmed sum of counts per minute: difference (week set 1-week set 2) versus average of values measured in week set 1 and week set 2 with $95 \%$ limits of agreement (mean, $\pm 1.96 \times$ standard deviation). WS1 week set 1 consisting of Monday, Tuesday, Wednesday; WS2 week set 2 consisting of Thursday, Friday, Saturday; $C P M$ counts per minute, solid horizontal line average of differences of WS1 and WS2, dashed horizontal lines $95 \%$ limits of agreement (mean difference, $\pm 1.96 \times$ standard deviation)

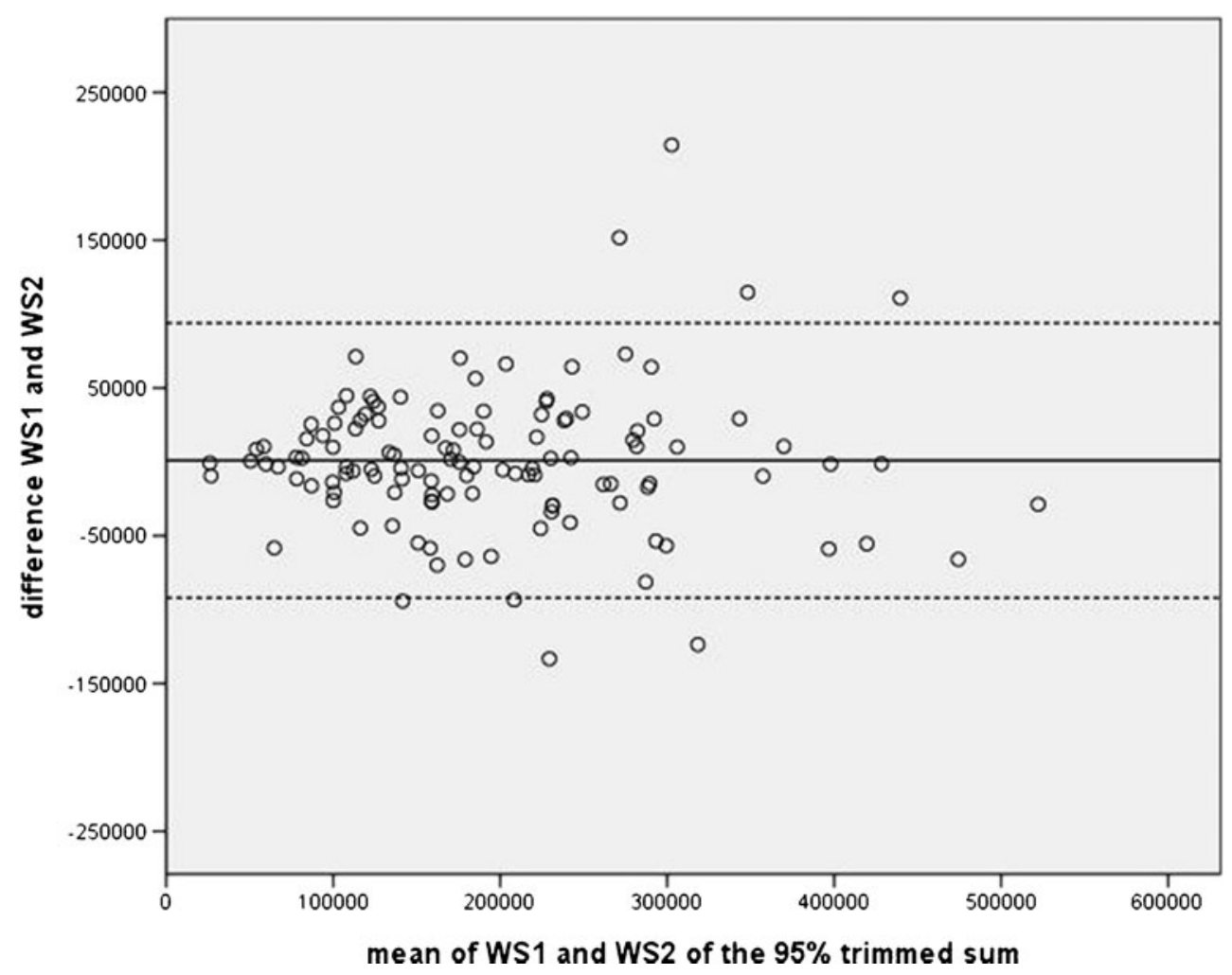

Summing up, the advantage of the trimmed sum is that it includes both the average level of activity and more intense effort, whereas a quantile would only measure the peak of more intense activities. Even though the TS95 did not show the highest retest reliability, it seems to be the most conservative estimator of the physical activity. Virtually all measurement errors are eliminated, while all background level and intensive activities are still included. Summing up, the TS95 appears to be an appropriate measurement value for demonstrating the physical activity level of older adults.

Besides the introduced recommendation on dealing with outliers, we would like to compare the retest reliability of our study to others implemented on the same target group. With special regard to other manufacturers of wrist-worn accelerometers, Gao and Tsang [8] found a high retest reliability of the mean CPM in their study on 3-day measurements on 12 people ( $\mathrm{ICC}=0.98$; $95 \% \mathrm{CI}$ : 0.93-0.99). These older participants, aged $79.8 \pm 11.2$ years, wore the uniaxial Actiwatch accelerometer (Mini Mitter Co., Inc., Bend, OR, USA) on the wrist for the same 3 days during two consecutive weeks. Harris et al. [10] found a comparably high agreement of a 7-day measurement with the Actigraph uniaxial accelerometer (GT1M; Manufacturing Technology Inc), worn on the hip by 20 participants (mean age about 74 years) with Pearson's $r=0.87$. They repeated the measurement after 2 months.
These two studies both have a more laboratory character compared to our study, since the measurement was repeated on the same days of two consecutive weeks or a whole week after 2 months. In contrast, we took the same week and split it into half (Sunday excluded). With our results on retest reliability, we were able to demonstrate that it is not compulsory to measure physical activity on the same half of the week. Moreover, we also included Saturdays in our analysis, even though activities on a Saturday may be different to the rest of the week. We assumed that participants would be less active on Saturdays compared to Monday to Friday. If this was true, our results on retest reliability would be negatively influenced and would have been even higher, if we had not included Saturdays in the analysis. These two differences in the study design might have relevance for further studies.

\section{Perspectives}

Accelerometry is a method widely applied to assess physical activity in studies $[17,22,27]$ and it will often be used in the future. Our recommendation of using the trimmed sum (e.g., $95 \%$ ) as a conservative estimate of the physical activity level of older adults would increase the quality of data by controlling for measurement errors. 
Acknowledgments The trial is funded by the German Federal Ministry of Education and Research (BMBF). The present study has been conducted within the PRISCUS research cooperation ("Prerequisites for a new health care model for elderly people with multimorbidity", 01ET0720).

Open Access This article is distributed under the terms of the Creative Commons Attribution License which permits any use, distribution, and reproduction in any medium, provided the original author(s) and the source are credited.

\section{References}

1. Ainsworth BE (2009) How do I measure physical activity in my patients? Questionnaires and objective methods. Br J Sports Med 43(1):6-9

2. Armitage P, Berry G, Matthews JNS (2001) Statistical methods in medical research. Blackwell, Malden

3. Bland JM, Altman DG (1999) Measuring agreement in method comparison studies. Stat Methods Med Res 8(2):135-160

4. Carvalho-Bos SS, Riemersma-van der Lek RF, Waterhouse J, Reilly T, Van Someren EJW (2007) Strong association of the rest-activity rhythm with well-being in demented elderly women. Am J Geriatr Psychiatry 15(2):92-100

5. Chen KY, Bassett DR (2005) The technology of accelerometrybased activity monitors: current and future. Med Sci Sports Exerc $37: 490-500$

6. Chipperfield JG, Newall NE, Chuchmach LP, Swift AU, Haynes TL (2008) Differential determinants of men's and women's everyday physical activity in later life. J Gerontol B Psychol Sci Soc Sci 63:211-218

7. Fries JF (1996) Physical activity, the compression of morbidity, and the health of the elderly. J R Soc Med 89(2):64-68

8. Gao KL, Tsang WWN (2008) Use of accelerometry to quantify the physical activity level of the elderly. Hong Kong Physiother J 26:18-23

9. Garatachea N, Luque GT, Gallego JG (2010) Physical activity and energy expenditure measurements using accelerometers in older adults. Nutr Hosp 25:224-230

10. Harris TJ, Owen CG, Victor CR, Adams R, Ekelund U, Cook DG (2009) A comparison of questionnaire, accelerometer, and pedometer: measures in older people. Med Sci Sports Exerc 41:1392-1402

11. Hinrichs T, Trampisch U, Burghaus I, Endres H, Klaassen-Mielke R, Moschny A, Platen P (2010) Correlates of sport participation among community-dwelling elderly people in Germany: a crosssectional study. Eur Rev Aging Phys Act 7(2):105-115

12. Manini TM, Everhart JE, Patel KV, Schoeller DA, Colbert LH, Visser M, Tylavsky F, Bauer DC, Goodpaster BH, Harris TB (2006) Daily activity energy expenditure and mortality among older adults. JAMA 296:171-179

13. Marazzi A, Ruffieux C (1999) The truncated mean of an asymmetric distribution. Comput Stat Data Anal 32(1):79-100

14. Mathie MJ, Coster ACF, Lovell NH, Celler BG (2004) Accelerometry: providing an integrated, practical method for long-term, ambulatory monitoring of human movement. Physiol Meas 25(2):1-20
15. McGraw KO, Wong SP (1996) Forming inferences about some intraclass correlations coefficients. Psychol Methods 1(1):30-46

16. Murphy SL (2009) Review of physical activity measurement using accelerometers in older adults: considerations for research design and conduct. Prev Med 48(2):108-114

17. Orsini N, Bellocco R, Bottai M, Hagstromer M, Sjostrom M, Pagano M, Wolk A (2008) Profile of physical activity behaviors among Swedish women aged 56-75 years. Scand J Med Sci Sports 18(1):95-101

18. Prince SA, Adamo KB, Hamel ME, Hardt J, Gorber SC, Tremblay M (2008) A comparison of direct versus self-report measures for assessing physical activity in adults: a systematic review. Int $\mathrm{J}$ Behav Nutr Phys Act 5:56

19. Rowe D, Kemble C, Birkenmeyer M, Mahar M (2008) Interinstrument and interposition agreement for the Actiband accelerometer during walking and running in 10-11 year old boys. Med Sci Sports Exerc 40:200

20. Shephard RJ (2003) Limits to the measurement of habitual physical activity by questionnaires. Br J Sports Med 37(3):197-206

21. Steele BG, Belza B, Cain K, Warms C, Coppersmith J, Howard J (2003) Bodies in motion: monitoring daily activity and exercise with motion sensors in people with chronic pulmonary disease. $\mathrm{J}$ Rehabil Res Dev 40(5):45-58

22. Sundquist K, Eriksson U, Kawakami N, Skog L, Ohlsson H, Arvidsson D (2011) Neighborhood walkability, physical activity, and walking behavior: the Swedish Neighborhood and Physical Activity (SNAP) study. Soc Sci Med 72(8):1266-1273

23. Trampisch US, Platen P, Burghaus I, Moschny A, Wilm S, Thiem U, Hinrichs T (2010) Reliabilität des PRISCUS-PAQ. Fragebogen zur erfassung körperlicher aktivität von personen im alter von 70 jahren und älter. Z Gerontol Geriatr 43(6):399-406. doi:10.1007/ s00391-010-0118-5

24. Trampisch US, Platen P, Moschny A, Hinrichs T (2011) Die eignung von fragebögen zur erfassung der körperlichen aktivität älterer erwachsener für den einsatz in einer epidemiologischen studie. Deutsche Zeitschrift für Sportmedizin 62(10):329-333

25. Trampisch US, Platen P, Moschny A, Wilm S, Thiem U, Hinrichs $T$ (2012) Messung körperlicher aktivität bei älteren erwachsenen: übereinstimmung zwischen PRISCUS-PAQ und akzelerometrie. Z Gerontol Geriatr. doi:10.1007/s00391-011-0264-4

26. Troiano RP, Berrigan D (2008) Physical activity in the United States measured by accelerometer: comment-response. Med Sci Sports Exerc 40(6):1189-1189

27. Troiano RP, Berrigan D, Dodd KW, Masse LC, Tilert T, McDowell M (2008) Physical activity in the United States measured by accelerometer. Med Sci Sports Exerc 40(1):181-188

28. Trost SG, McIver KL, Pate RR (2005) Conducting accelerometerbased activity assessments in field-based research. Med Sci Sports Exerc 37:531-543

29. Tudor-Locke C, Burkett L, Reis JP, Ainsworth BE, Macera CA, Wilson DK (2005) How many days of pedometer monitoring predict weekly physical activity in adults? Prev Med 40:293-298

30. Washburn RA, Ficker JL (1999) Physical Activity Scale for the Elderly (PASE): the relationship with activity measured by a portable accelerometer. J Sports Med Phys Fitness 39(4):336-340

31. Washburn RA, McAuley E, Katula J, Mihalko SL, Boileau RA (1999) The physical activity scale for the elderly (PASE): evidence for validity. J Clin Epidemiol 52:643-651 